\title{
A specific IgG in Graves' ophthalmopathy and its relation to retro-orbital and thyroid autoimmunity
}

\author{
PAT KENDALL-TAYLOR, STEPHEN ATKINSON, MENNA HOLCOMBE
}

\begin{abstract}
An IgG (ophthalmopathic immunoglobulin) that binds to retro-orbital antigen was identified in serum from patients with active Graves' ophthalmopathy, and its nature and specificity were investigated. Dose related binding of this immunoglobulin to retro-orbital antigens prepared from guinea pig harderian gland or porcine eye muscle was found, which could be abolished by prior incubation with antigen. The immunoglobulin did not bind to thyroid membranes, thyroid microsomes, or thyroglobulin or interact with liver, skeletal muscle, or fat membranes. Serum with high activity of thyrotrophin binding inhibiting immunoglobulin did not react with retro-orbital antigen, and this activity was not affected by preincubation of the serum with retro-orbital antigen. Thyroid stimulating hormone was also without effect on retro-orbital antigen.

It is concluded that Graves' ophthalmopathy is associated with a specific ophthalmopathic immunoglobulin that reacts with retro-orbital antigen as distinct from thyroid antigens, and that the autoimmune response is directed towards retro-orbital antigens. This suggests that the ophthalmopathy is an entity distinct from autoimmune thyroid disease.
\end{abstract}

\section{Introduction}

The association of ophthalmopathy with Graves' disease is well known, but, whereas the pathogenesis of hyperthyroidism has

\footnotetext{
Endocrine Unit, Department of Medicine, Royal Victoria Infirmary, Newcastle upon Tyne NE1 4LP

PAT KENDALL-TAYLOR, MD, FRCP, reader

STEPHEN ATKINSON, PHD, research associate

MENNA HOLCOMBE, BSC, biochemist

Correspondence to: Dr P Kendall-Taylor.
}

become clear in recent years, the explanation for the ophthalmopathy has been elusive. Graves' ophthalmopathy occurs in patients with hyperthyroidism (active or treated), occasionally with primary hypothyroidism, and sometimes in the absence of thyroid disease. Therefore it has been postulated that it is a distinct organ specific autoimmune disease. Current treatment is not very satisfactory, and improved management will depend on a better understanding of the pathogenesis. To this end there have been several studies of retro-orbital antigens and of $T$ cell or humoral responses to them: cell mediated immunity has been found in patients with ophthalmic Graves' disease using guinea pig or human retro-orbital antigens ${ }^{12}$; monoclonal antibodies were used to study various human retro-orbital antigens ${ }^{3}$; and circulating autoantibodies were found using a soluble human eye muscle antigen.

In this study we investigated the relation of ophthalmopathy to thyroid disease by examining, firstly, the specificity of the binding of ophthalmopathic immunoglobulin to retro-orbital antigens and, secondly, the interactions of thyroid antibodies, including the receptor antibody responsible for hyperthyroidism, with retro-orbital antigens.

\section{Methods}

\section{SERUM SAMPLES}

For this study laboratory standards of ophthalmopathic immunoglobulin were used. They were obtained from two patients with severe ophthalmopathy and were selected from several serum samples known to contain easily detectable ophthalmopathic immunoglobulin because they were free of microsomal and thyroglobulin antibodies.

Case 1-Serum containing ophthalmopathic immunoglobulin activity was obtained from a woman born in 1923 who developed hyperthyroidism and exophthalmos in 1950. She underwent thyroidectomy but thereafter required antithyroid drugs, and subsequently she received external irradiation to the neck followed by three doses of iodine-131. Hyperthyroidism persisted, and in 1975 she received a further $16 \mathrm{mCi}$ dose of ${ }^{131} \mathrm{I}$. The ophthalmopathy deteriorated, and she was treated with external irradiation to the orbits in 1975; steroids were started in 1976, and she underwent corneal grafting and eventual unilateral enucleation in 1978. In 1983 she was euthyroid while taking thyroxine $50 \mu \mathrm{g}$ daily. Her remaining eye showed continuing active ophthalmopathy. There was a strong family history of auto- 
immune thyroid disease: two of her five siblings, her mother, and three of her mother's eight siblings were affected. She carried the HLA A1, B8, DR3 haplotype.

Case 2-Serum containing ophthalmopathic immunoglobulin activity was ubtained from a man born in 1912 who was healthy until March 1981, when, after undergoing nephrectomy for hydronephrosis, he complained of sore, prickly eyes. By July 1981 he had pronounced bilateral proptosis and active ophthalmopathy but was clinically and biochemically euthyroid. In August the ophthalmopathy was more severe with ophthalmoplegia and he had become minimally thyrotoxic (serum thyroxine concentration $149 \mathrm{nmol} / 1(11.6 \mu \mathrm{g}$ / $100 \mathrm{ml}$ ) (normal range $<150 \mathrm{nmol} / 1(<11.7 \mu \mathrm{g} / 100 \mathrm{ml})$ ), triiodothyronine concentration $4.7 \mathrm{nmol} / 1(3.1 \mathrm{ng} / \mathrm{ml}$ ) (normal range $<3 \mathrm{nmol} / 1(<2 \cdot 0 \mathrm{ng} / \mathrm{ml})$ ), and flat response to a thyrotrophin releasing hormone test); an isotope scan showed as light diffuse increase in thyroidal uptake.

Serum was also obtained from patients with a high titre of thyrotrophin binding inhibiting immunoglobulin but without ophthalmopathy, as well as from healthy subjects. All serum samples were stored in aliquots at $-40^{\circ} \mathrm{C}$. Thyroglobulin and microsomal antibodies were assayed with Fujizoki kits. Thyrotrophin binding inhibiting immunoglobulin was measured in a receptor binding assay, ${ }^{4}$ modified by the use of solubilised receptors for thyroid stimulating hormone.

\section{PREPARATION OF ANTIGEN}

Retro-orbital fractions were prepared from porcine retro-orbital muscle and guinea pig harderian glands and used as antigens to coat microwell plates for an enzyme linked immunosorbent assay. Porcine retro-orbital muscle was used in preference to human tissue as adequate amounts of fresh tissue are readily available. Guinea pig harderian gland was also examined as it has been used as a model in several previous studies of Graves' ophthalmopathy. ${ }^{5-7}$

Retro-orbital tissue was dissected free of fat and connective tissue and homogenised in five volumes of buffer containing trometamol (TRIS) $10 \mathrm{mmol} / 1$ and sodium chloride $50 \mathrm{mmol} / \mathrm{l}(\mathrm{pH} \mathrm{7.4})$ in a polytron blender at $4^{\circ} \mathrm{C}$. The homogenates were centrifuged at $800 \mathrm{~g}$ for 10 minutes at $4^{\circ} \mathrm{C}$ and the resulting supernatant centrifuged at $10000 \mathrm{~g}$ for 20 minutes at $4^{\circ} \mathrm{C}$. The pellet from this centrifugation was resuspended in trometamol-sodium chloride buffer and used in experiments of membrane absorption. The supernatant from the $10000 \mathrm{~g}$ spin was further centrifuged at $100000 \mathrm{~g}$ for 60 minutes at $4^{\circ} \mathrm{C}$ and the pellet resuspended in trometamolsodium chloride buffer and used to coat microwell plates. The protein concentrations of the membrane fraction and the $100000 \mathrm{~g}$ retro-orbital antigen were estimated by the method of Lowry. Both fractions were stored in aliquots at $-70^{\circ} \mathrm{C}$ until use.

For specificity studies tissue was obtained from guinea pig and porcine thyroid, liver, heart muscle, skeletal muscle, and fat. After homogenisation $10000 \mathrm{~g}$ and $100000 \mathrm{~g}$ fractions were prepared as above and used either to coat microwell plates for an enzyme linked immunosorbent assay or for experiments of immunoglobulin absorption. Human thyroid microsomes were prepared as previously described, ${ }^{8}$ and porcine thyroglobulin was obtained commercially (Sigma).

Pretreatment of serum by absorption to porcine red blood cells was as follows. Pig blood was semidiluted in Alsever's solution $(0.42 \%$ sodium chloride, $0.8 \%$ sodium citrate, $2.05 \%$ glucose) and centrifuged at $800 \mathrm{~g}$ for five minutes at $4^{\circ} \mathrm{C}$; the pellet was washed three times in $0.95 \%$ saline and finally resuspended in saline. The suspension was incubated with serum for 60 minutes at $37^{\circ} \mathrm{C}$, the red blood cells then pelleted, and the supernatant used in the enzyme linked immunosorbent assay.

\section{ENZYME LINKED IMMUNOSORBENT ASSAY}

Microwell plates (Flow, Limbro) were coated with retro-orbital antigens $(10 \mu \mathrm{g} / \mathrm{l})$ in carbonate buffer $\mathrm{pH} 9.6$ by overnight incubation at $4^{\circ} \mathrm{C}$. Serum was applied diluted in phosphate buffer $\mathrm{pH} 7 \cdot 4$ (120 minutes' incubation at room temperature). The enzyme used was horseradish peroxidase conjugated to porcine antihuman IgG (Orion Diagnostics) (120 minutes' incubation at room temperature), with $o$-phenylene diamine as substrate ( 30 minutes' incubation at room temperature in the dark). Optical densities (492 $\mathrm{nm}$ ) were measured (Flow Titertek Multiskan) on triplicates for each sample

\footnotetext{
with appropriate controls.
}

\section{Results}

Neither of the standard sera showing ophthalmopathic immunoglobulin activity contained detectable thyroglobulin antibodies or microsomal antibodies at any stage of serial sampling. Both sera had demonstrable activity of thyrotrophin binding inhibiting immunoglobulin (55 units in case 1,31 units in case 2 (normal reference range $<15$ units)).

The figure shows the dose dependent relation between the concentration of ophthalmopathic immunoglobulin (case 1) and binding
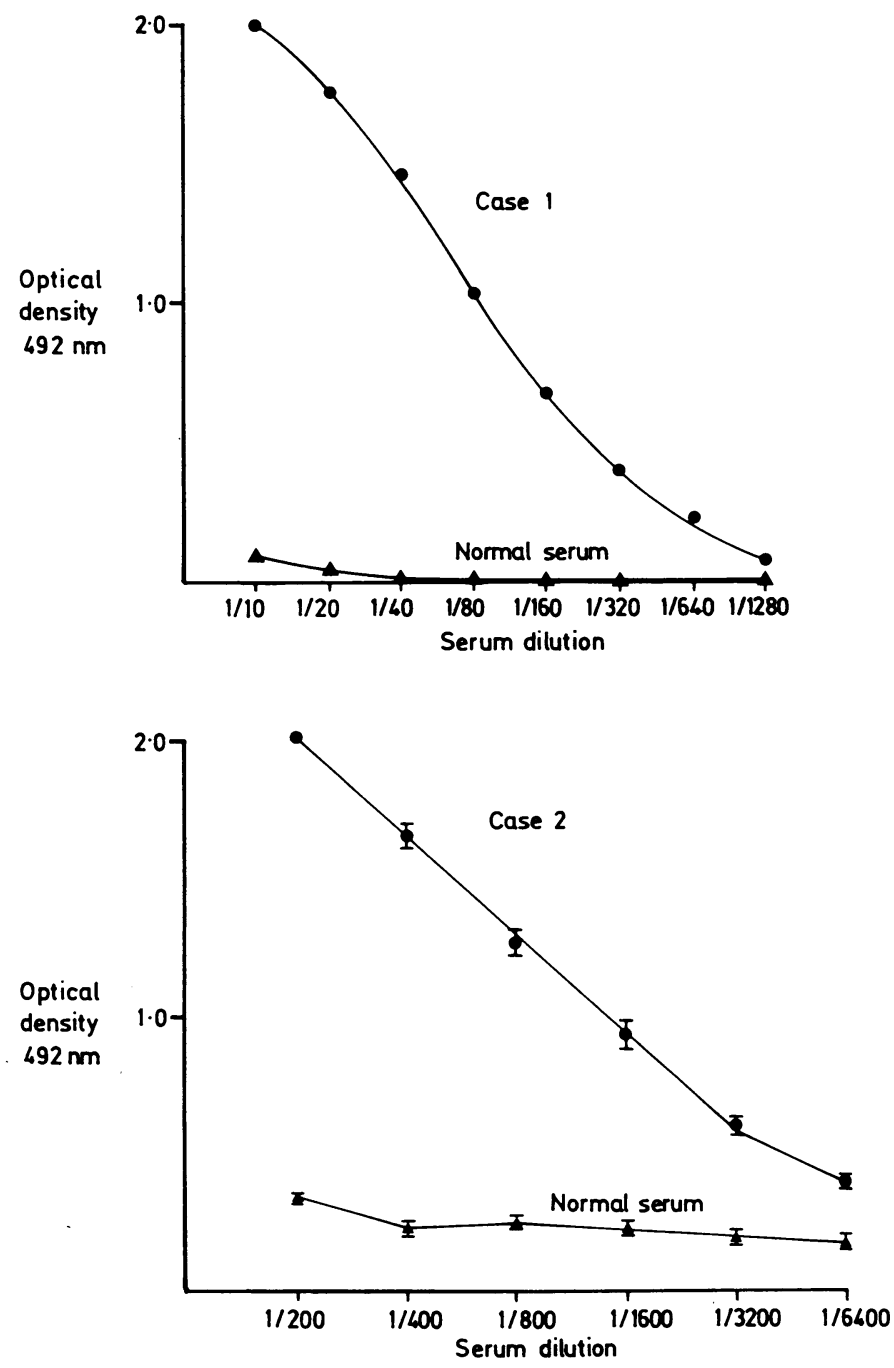

Top: Binding of ophthalmopathic immunoglobulin (case 1) or IgG in pooled normal serum to guinea pig harderian gland antigen (100 000 g fraction; $10 \mu \mathrm{g} / \mathrm{ml}$ ), measured by optical density of microwells in enzyme linked immunosorbent assay. Bottom: Binding of ophthalmopathic immunoglobulin (case 2) to porcine eye muscle antigen (100 $000 \mathrm{~g}$ fraction; $10 \mu \mathrm{g} / \mathrm{ml})$.

to guinea pig harderian antigen and the similar relation between ophthalmopathic immunoglobulin (case 2) and porcine retro-orbital antigen. Specific binding was detected at serum dilutions of up to $1 / 1280$ and $1 / 6400$ respectively. The absence of specific binding of IgG from pooled normal serum is also shown for both antigens.

Individual serum samples from 40 healthy subjects (diluted $1 / 100$ ) gave a normal range of optical densities of $<0.29 \mathrm{~nm}$ with guinea pig harderian antigen and of $<0.37 \mathrm{~nm}$ with porcine retroorbital muscle antigen.

Table I shows binding of serum from case 1 and of pooled normal serum to $100000 \mathrm{~g}$ antigen preparations from various guinea pig tissues coated on microwell plates. Only in the case of the retro-orbital antigen prepared from harderian glands was binding of serum containing ophthalmopathic immunoglobulin activity appreciably 
TABLE I-Mean (SD) binding of serum containing ophthalmopathic immunoglobulin (OIg) and of pooled normal serum $(n=3)$ to various guinea pig tissue $100000 \mathrm{~g}$ fractions coated on to microwell plates at concentrations of 5,10 , and $20 \mu \mathrm{g} / \mathrm{ml}$ (optical density at $492 \mathrm{~nm}$ )

\begin{tabular}{|c|c|c|c|}
\hline Coating antigen & $\begin{array}{l}\text { Concentration } \\
(\mu \mathrm{g} / \mathrm{ml})\end{array}$ & $\begin{array}{l}\text { Pooled normal } \\
\text { serum }\end{array}$ & $\begin{array}{c}\text { Serum containing } \mathrm{OIg} \\
(\text { case } 1)\end{array}$ \\
\hline None & & $0.159(0.030)$ & $0.063(0.011)$ \\
\hline Harderian gland & $\begin{array}{r}3 \\
10 \\
20 \\
5\end{array}$ & $\begin{array}{l}0.408(0.004) \\
0.472(0.003) \\
0.466(0.009) \\
0.538(0.009)\end{array}$ & $\begin{aligned} & 1.892(0.049) \\
&> 2 \\
& 0.124(0.016)\end{aligned}$ \\
\hline Thyroid & $\begin{array}{r}10 \\
20 \\
5\end{array}$ & $\begin{array}{l}0.557(0.021) \\
0.625(0.020) \\
0.404(0.006)\end{array}$ & $\begin{array}{l}0.124(0.010) \\
0.138(0.017) \\
0.186(0.025) \\
0.327(0.011)\end{array}$ \\
\hline Liver & $\begin{array}{r}10 \\
20 \\
5\end{array}$ & $\begin{array}{l}0.453(0.022) \\
0.446(0.026) \\
0.548(0.016)\end{array}$ & $\begin{array}{l}0.442(0.031) \\
0.639(0.025) \\
0.440(0.010)\end{array}$ \\
\hline Skeletal muscle & $\begin{array}{r}10 \\
20 \\
5\end{array}$ & $\begin{array}{l}0.608(0.032) \\
0.726(0.035) \\
0.425(0.014)\end{array}$ & $\begin{array}{l}0.408(0.040) \\
0.399(0.0) \\
0.532(0.027)\end{array}$ \\
\hline Heart & $\begin{array}{r}10 \\
20 \\
5\end{array}$ & $\begin{array}{l}0.429(0.009) \\
0.472(0.012) \\
0.489(0.025)\end{array}$ & $\begin{array}{l}0.267(0.017) \\
0.334(0.022) \\
0.322(0.010)\end{array}$ \\
\hline Fat & $\begin{array}{l}10 \\
20\end{array}$ & $\begin{array}{l}0.580(0.012) \\
0.550(0.022)\end{array}$ & $\begin{array}{l}0.487(0.009) \\
0.651(0.024)\end{array}$ \\
\hline
\end{tabular}

greater than that of pooled normal serum, indicating specificity for retro-orbital tissue. The greater degree of binding of pooled normal serum to thyroid $100000 \mathrm{~g}$ antigen compared with ophthalmopathic immunoglobulin is unexplained but might reflect undetected thyroid antibodies in a member of the normal pool. The binding of serum from case 2 to porcine thyroid, liver, heart muscle, skeletal muscle, and fat was also investigated, and in all tissues examined was slightly greater than the binding of pooled normal serum; but the binding of serum from case 2 to retro-orbital antigen was two to three times greater than binding to other tissue antigens. The serum was pretreated by absorption to porcine red blood cells to reduce non-specific binding to porcine tissues (Forssman antibody effect), but this had no effect on binding to porcine retro-orbital antigen.

The tissue specificity of ophthalmopathic immunoglobulin was further investigated by attempting to absorb out antigen binding activity by preincubation of serum with membrane preparations from various tissues. Preincubation of serum from case $1(0.045 \mu \mathrm{l} / \mathrm{ml})$ with increasing concentrations of harderian gland membranes considerably reduced IgG binding to $100000 \mathrm{~g}$ harderian antigen. Preincubation with guinea pig tissue membranes prepared from thyroid, liver, skeletal muscle, and fat had no appreciable effect on IgG binding, with the exception of liver membranes at high concentration $(10 \mathrm{mg} / \mathrm{ml})$. Similarly, prior incubation with human thyroid membranes at concentrations of up to $6 \mathrm{mg} / \mathrm{ml} \mathrm{had} \mathrm{no} \mathrm{effect} \mathrm{on} \mathrm{activity}$ of ophthalmopathic immunoglobulin. Porcine thyroglobulin and human thyroid microsomes also failed to neutralise activity of ophthalmopathic immunoglobulin. The binding of serum from case 2 to porcine retro-orbital antigen was considerably reduced by preincubation with membranes prepared from porcine eye muscle but not by membranes prepared from porcine thyroid, liver, heart muscle, skeletal muscle, or fat or by human thyroid membranes, human thyroid microsomes, or porcine thyroglobulin.

Preincubation of serum containing ophthalmopathic immunoglobulin with retro-orbital membranes had no effect on activity of thyrotrophin binding inhibiting immunoglobulin (table II). The serum was preincubated with guinea pig harderian gland, thyroid, and skeletal muscle membranes $(1 \mathrm{mg} / \mathrm{ml}$ ); after centrifugation $\mathrm{IgG}$ was prepared from the supernatant and thyrotrophin binding inhibiting immunoglobulin estimated. Preincubation with harderian gland and skeletal muscle membranes had no effect on activity of

TABLE II-Mean (SD) thyrotrophin binding inhibiting immunoglobulin activity of serum containing ophthalmopathic immunoglobulin (OIg) (expressed as \% inhibition of binding of thyroid stimulating hormone labelled with ${ }^{125} I\left({ }^{125} I-T S H\right)$ after incubation with harderian gland, thyroid, and skeletal muscle membranes $(10000 \mathrm{~g}$ fractions, $1 \mathrm{mg} / \mathrm{ml}$ )

\begin{tabular}{lc}
\hline & $\%$ inhibition of ${ }^{125}$ I-TSH binding \\
\hline $\begin{array}{l}\text { Pooled normal serum } \\
\text { Serum containing OIg }\end{array}$ & $0.5(2 \cdot 1)$ \\
Serum containing OIg after incubation with & $55.0(3 \cdot 0)$ \\
$\quad$ membrane preparations from: & \\
Thyroid & $36.5(2.5)^{*}$ \\
Harderian gland & $55.0(3 \cdot 1)$ \\
Skeletal muscle & $51.0(3.8)$ \\
\hline
\end{tabular}

*Significance of difference from serum containing OIg: $p<0.02$. thyrotrophin binding inhibiting immunoglobulin, whereas incubation with thyroid membranes reduced it (as measured by a reduced ability to inhibit binding of thyroid stimulating hormone labelled with ${ }^{125} \mathrm{I}$ to the hormone receptor). Furthermore, thyrotrophin binding inhibiting immunoglobulin obtained from eight patients with hyperthyroidism but without ophthalmopathy did not show any activity of ophthalmopathic immunoglobulin.

There was no binding of thyroid stimulating hormone to retroorbital tissue. When plates coated with harderian antigen were preincubated with bovine thyroid stimulating hormone (Thytropar, Armour Pharmaceuticals) at concentrations of $0,1,10$, and $100 \mathrm{U} / 1$ no appreciable change in binding of ophthalmopathic immunoglobulin to harderian antigen resulted (table III). Furthermore, the

TABLE III-Effect of thyroid stimulating hormone (TSH) on binding of ophthalmopathic immunoglobulin to harderian antigen. Results expressed as means (SEM) ( $n$ at 3; optical density at $492 \mathrm{~nm}$ )

\begin{tabular}{lcccc}
\hline & \multicolumn{4}{c}{ Preincubation concentration of TSH (U/1)* } \\
\cline { 2 - 5 } & 0 & 1 & 10 & 100 \\
\hline $\begin{array}{l}\text { Pooled normal serum } \\
\begin{array}{c}\text { Serum containing } \\
\text { ophthalmopathic } \\
\text { immunoglobulin (case 1) }\end{array}\end{array}$ & $1.627(0.014)$ & $1.534(0.022)$ & $1.554(0.016)$ & $1.561(0.036)$
\end{tabular}

*Plates coated with harderian antigen $(10 \mu \mathrm{g} / \mathrm{ml}$ ) were preincubated (for 60 minutes at room temperature) with bovine TSH at different concentrations. Serum was diluted $1 / 100$.

coincubation of thyroid stimulating hormone with ophthalmopathic immunoglobulin ( $2 \mathrm{mU}$ bovine thyroid stimulating hormone/100 $\mu 1$ serum) in other experiments had no effect on binding of the immunoglobulin to retro-orbital antigens.

\section{Discussion}

In this study an IgG (ophthalmopathic immunoglobulin) associated with Graves' ophthalmopathy was shown to bind to retro-orbital antigens in a dose related manner; this effect was not observed with normal serum. The immunoglobulin could be removed by prior incubation with retro-orbital antigen. The retro-orbital antigen is distinct from thyroid antigen as little or no IgG binding to various thyroid antigens occurred and the immunoglobulin was not absorbed by prior incubation with different thyroid fractions; in particular, it was not related to microsomal antibody or thyroglobulin antibody. Ophthalmopatnic IgG is also distinct from thyrotrophin binding inhibiting immunoglobulin and thyroid stimulating antibody, the antibody responsible for hyperthyroidism. ${ }^{9}$ Prior incubation with thyroid particulate membranes had no effect on activity of ophthalmopathic immunoglobulin, and incubation of thyrotrophin binding inhibiting immunoglobulin with retro-orbital antigen did not reduce activity of the thyrotrophin binding inhibiting immunoglobulin. Samples with a very high titre of thyrotrophin binding inhibiting immunoglobulin from patients without exophthalmos did not have ophthalmopathic immunoglobulin.

In a series of patients with thyroid or eye disease, or both, ophthalmopathic immunoglobulin correlated with the presence of active ophthalmopathy (S Atkinson et al, paper submitted for publication). Earlier work suggested a possible role for thyroid stimulating hormone or thyroid stimulating hormone fragments in the pathogenesis of Graves' ophthalmopathy ${ }^{1011}$; in our study, however, the hormone had no effect: it did not bind to retroorbital antigen, its addition to samples containing ophthalmopathic immunoglobulin did not alter the response, and preincubation of retro-orbital antigen with thyroid stimulating hormone did not have any effect on the subsequent binding of ophthalmopathic immunoglobulin to antigen. Immunoglobulins specific to Graves' disease interact similarly with porcine thyroid tissue and with human thyroid, ${ }^{12} 13$ suggesting antigenic similarity; thus the use of porcine retro-orbital eye muscle seemed reasonable. 
Graves' ophthalmopathy is generally regarded as an organ specific autoimmune disease, ${ }^{14}$ probably distinct from thyroid autoimmune disease though closely related to it. The pathogenesis is not known. It occurs most commonly with hyperthyroidism but is also found in patients with primary myxoedema, with Hashimoto's thyroiditis, or with no thyroid disease at all, and the severity of the condition does not correlate with thryroid function. ${ }^{15-17}$ There is poor correlation of thyroid antibodies with ophthalmopathy, and in particular immunoglobulins specific to Graves' disease such as thyrotrophin binding inhibiting immunoglobulin and long acting thyroid stimulator protector are not found with any consistency. ${ }^{16-18}$ Attempts to neutralise long acting thyroid stimulator with retro-orbital antigens were unsuccessful. ${ }^{19}$ Our work supports the view that thyrotrophin binding inhibiting immunoglobulin, long acting thyroid stimulator, and long acting thyroid stimulator protector are not directly associated with Graves' ophthalmopathy and is consistent with the hypothesis that ophthalmopathy is a distinct entity.

There have been several previous attempts to show immune disturbance related to retro-orbital antigens. Munro et al showed cellular immunity, using the migration inhibition factor test, against retro-orbital antigens in patients with ophthalmopathy and found that this could be distinguished from the response of migration inhibition factor to thyroidal antigens in patients with autoimmune thyroid disease. ${ }^{2}$ Our finding of a specific IgG, indicating a $B$ cell response to retro-orbital antigens, is consistent with this. Konishi et al reported an affinity of retro-orbital muscle for thyroglobulin and for thyroglobulin-antithyroglobulin complexes ${ }^{20}$; Mullin et al found that the autoantigen in the migration inhibition factor test was chemically similar to thyroglobulin. ${ }^{21}$ The importance of these findings is not clear, particularly as many patients have either no thyroglobulin antibody or no thyroid disease. In our study the IgG could not be absorbed with thyroglobulin even at high concentration. More recently, Kodama et al produced monoclonal antibodies to various retro-orbital antigens and used them to study the nature of the antigen in patients with ophthalmopathy. ${ }^{3}$ They found a tendency for these monoclonal antibodies to eye muscle to cross react with skeletal muscle, and in one case there was cross reactivity with thyroid microsomes. Some patients with ophthalmopathy were observed to have circulating antibody (ophthalmopathic immunoglobulin) to soluble antigen derived from eye muscle.

Our work confirms the finding of an ophthalmopathic immunoglobulin in serum of patients with Graves' ophthalmopathy and shows the specific nature of this immunoglobulin as distinct from thyroid antibodies, suggesting that the autoimmune response is directed towards specific retro-orbital antigen. As yet there is no evidence that ophthalmopathic immunoglobulin is itself pathogenic, but the ability to detect this immunoglobulin will facilitate further studies of the pathogenic mechanisms for the development of ophthalmopathy, which should ultimately lead to more rational and more effective approaches to its management.

This work was supported by the Medical Research Council and the Newcastle Health Authority.

\section{References}

${ }^{1}$ Mahieu R, Winand R. Demonstration of delayed hypersensitivity in retrobulbar and thyroid tissues in human exophthalmos. $\mathcal{f}$ Clin Endocrinol Metab 1972;34:1090-2.

${ }^{2}$ Munro RE, Lamki L, Row VV, Volpé R. Cell mediated immunity in the exophthalmos of Graves' disease as demonstrated by the migration inhibition factor (MIF) test. 7 Clin Endocrinol Metab 1973;37:286-92.

${ }^{3}$ Kodama K, Sikorska H, Bandy-Dafoe P, Bayly R, Wall JR. Demonstration of a circulating autoantibody against a soluble eye-muscle antigen in Graves' ophthalmopathy. Lancet 1982 ;ii:1353-6.

4 Smith BR, Hall R. Thyroid stimulating immunoglobulins in Graves' disease. Lancet 1974 ;ii:427-30.

5 Pisarev MA, Altschuler N, Davison TA. Immune exophthalmos due to harderian gland antigen. Endocrinology 1968;83:903-6.
${ }^{6}$ Singh SP, McKenzie JM. Studies of homologous immunisation with mouse harderian gland. Metabolism 1971;20:293-8.

7 Winand JR, Kohn LD. Retrobulbar modifications in experimental exophthalmos: the effect of thyrotropin and an exophthalmos-producing substance derived from thyrotropin in the ${ }^{35} \mathrm{SO}_{4}$ incorporation and glycosaminoglycan content of harderian glands. Endocrinology 1973; $93: 670-80$.

${ }^{8}$ Goodburn R, Williams DL, Marks V. The preparation of thyroid microsomal antigen for use in the indirect micro ELISA method for the detection of antithyroid microsomal antibody. Clin Chim Acta 1982; 119:291-7.

${ }^{9}$ Kendall-Taylor P. The pathogenesis of hyperthyroidism. In: Tunbridge WMG, ed. Advanced medicine, Royal College of Physicians of London, Newcastle upon Tyne. London: Pitman Medical, 1981:14-22.

10 Winand RJ, Kohn LD. Relationship of thyrotropin to exophthalmicproducing substance. Purification of homogeneous glycoproteins containing both activities from ${ }^{3} \mathrm{H}$-labelled pituitary extracts. $\mathcal{F}$ Biol Chem 1970;245:967-75.

${ }^{11}$ Bolonkin D, Tate RL, Luber JH, Kohn LD. Experimental exophthalmosbinding of thyrotropin and an exophthalmogenic factor derived from thyrotrophin to retro-orbital tissue plasma membranes. $\mathcal{F} \mathrm{Biol}$ Chem $1975 ; 250: 6515-21$.

12 Davies TF. Autoantibodies to the human thyrotropin receptor are not species specific. $\mathcal{F}$ Clin Endocrinol Metab 1981;54:426-30.

${ }^{13}$ Humphries H, Dirmikis SM, Munro DS. Comparison of human and porcine thyroid membranes for radio-receptor assay of bovine thyrotrophin and thyrotrophin-binding inhibiting immunoglobulins. $\mathcal{f}$ Endocrinol $1982 ; 93: 371-80$.

14 Volpé R. The pathogenesis of Graves' disease: an overview. Clin Endocrinol Metab 1978;7:3-29.

${ }^{15}$ McKenzie JM, McCullagh EP. Observations against a causal relationship between the long acting thyroid stimulator and ophthalmopathy in Graves' disease. $\mathcal{f}$ Clin Endocrinol Metab 1968;28:1177-82.

${ }^{16}$ Solomon DH, Chopra IJ, Chopra U, Smith FJ. Identification of subgroups of euthyroid Graves' ophthalmopathy. $N$ Engl f Med 1977; $296: 181-6$.

17 Teng CS, Smith BR, Clayton B, Evered DC, Clark F, Hall R. Thyroid stimulating immunoglobulins in ophthalmic Graves' disease. Clin Endocrinol 1977;6:207-11.

${ }^{18}$ Wall JR, Strakosch CR, Fang SL, Ingbar SH, Braverman LE. Thyroid binding antibodies and other immunological abnormalities in patients with Graves' ophthalmopathy: effect of treatment with cyclophosphamide. Clin Endocrinol 1979;10:79-91.

${ }^{19}$ Shillinglaw J, Utiger RD. Failure of retro-orbital tissue to neutralise the biological activity of the long-acting thyroid stimulator. $\mathcal{F}$ Clin Endocrinol Metab 1968;28:1069-70.

${ }^{20}$ Konishi J, Herman MM, Kriss JP. Binding of thyroglobulin and thyroglobulin-antithyroglobulin immune complex to extra-ocular muscle membrane. Endocrinology $1974 ; 95: 434-46$.

${ }^{21}$ Mullin BR, Levinson RE, Freidman A, Henson DE, Winand RJ, Kohn LD. Delayed hypersensitivity in Graves' disease and exophthalmos: identification of thyroglobulin in normal human orbital muscle. Endocrinology 1977;100:351-66.

(Accepted 31 Fanuary 1984)

ONE HUNDRED YEARS AGO It is by no means an uncommon thing now for a schoolmaster to be summoned before magistrates on a charge of assaulting a pupil. There seems to be a misapprehension in the minds of many people as to what are the rights of schoolmasters and their pupils respectively in this matter. At common law, a master is considered as standing in loco parentis to his pupil, and is entitled to chastise him in the same way as a father might. This position may be varied by agreement between the parties; as, if a father stipulates with the schoolmaster that his son is not to be subject to corporal punishment, or if the rules of the school forbid the master administering it, or only allow him to do so in certain specified instances. In the absence of any such agreement, however, a master may, in his own discretion, administer reasonable chastisement to his pupils. If a complaint be brought against him in a court of justice, the question which the court ought to consider is, how far the chastisement which was administered was or was not reasonable, having regard to the circumstances of each particular case. This question is often by no means easy to decide; and the decisions given by different courts are by no means easy to reconcile with one another. But a good deal of ill feeling might be spared, and cases might with advantage be kept out of court which now are brought there, if boys and their parents would remember that masters have, prima facie, a right to chastise their pupils, and that a charge of assault can only be maintained if the punishment be excessive. (British Medical fournal $1884 ; \mathrm{i}: 232$.) 